\title{
Altered intrauterine ultrasound, fetal head circumference growth and neonatal outcomes among suspected cases of congenital Zika syndrome in Brazil
}

\author{
Alex Sandro Rolland Souza 1 \\ Ariani Impieri de Souza 2 \\ Silvia de Lourdes Loreto Faquin 3 \\ Orlando Gomes dos Santos Neto 4 \\ Emanuele Honorato 5 \\ Alice Góes Liberato Mattos 6 \\ Simone Cristina Holanda 7 \\ José Natal Figueiroa 8 \\ Juliana Schettini 9 \\ 1,2,4,5,8,9 Instituto de Medicina Integral Prof. Fernando Figueira (IMIP). Rua dos Coelhos, 300. Recife, PE, Brasil. CEP: 50.070-550. \\ E-mail: alexrolland@uol.com.br \\ 3 Universidade Federal de Pernambuco. Recife, PE, Brasi \\ 6,7 Faculdade Pernambucana de Saúde. Recife, PE, Brasil.
}

\begin{abstract}
Objectives: to describe altered intrauterine ultrasound, analyze fetal head circumference (HC) growth and neonates' outcomes among presumed cases of congenital Zika syndrome in Brazil.

Methods: 30 women were included in the study with suspected history of Zika virus (ZIKV) infection during pregnancy and fetal's brain altered on ultrasound diagnosis. Sociodemographic and obstetric characteristics, prenatal altered ultrasounds, HC and other perinatal outcomes have been described. The relation between $H C$ and gestational age was analyzed by using random regression effects based on polynomials fractions. The $Z$ test was calculated to determine an instant variant mean rate of the HC for each gestational age.

Results: the mean gestational age of the ultrasound diagnosis was $33.3+4.7$ weeks and $H C$ at birth was $28.9+1.6 \mathrm{~cm}$. The main altered brain ultrasound was microcephaly $(96.7 \%)$. The analysis of the fetal head circumference showed an estimated increase of the average $H C$, as to gestational age, it did not occur in a linear form. The instant HC variation rate increased according to gestational age $(p<0,001)$.

Conclusions: Fetal's main morphological alteration was microcephaly, observing an increase in the head circumference according to gestational age in a non-linear form and the variation decreased with gestational age.
\end{abstract}

Key words Microcephaly, Arbovirus infections, Prenatal diagnosis, Prenatal ultrasound 


\section{Introduction}

Recent studies have provided strong evidence of the association between the infection of Zika virus (ZIKV) during pregnancy and the development of microcephaly. ${ }^{1-5}$ The virus is transmitted by mosquitoes, particularly the Aedes species, ${ }^{4}$ by direct transmission among humans, perhaps sexual intercourse and as perinatal, all have been described.1,6

Serious consequences of arboviruses transmission to maternal-fetal have been reported, in particularly for Chikungunya (as being associated to hemorrhagic fever and encephalopathy) and dengue (leading to premature delivery, fetal death, low birth weight, fetal abnormalities, prematurity and acute fetal distress).7,8 However, until this moment there are no reports in the medical literature associating Zika virus with congenital anomalies, particularly, microcephaly. ${ }^{2}$

Recent studies have suggested a strong association of maternal infection by Zika virus with fetal anomalies, particularly of the brain, highlighting microcephaly, 2,3,9,10 as an association recognized by the Centers for Disease Control and Prevention of being a major public health problem.11

Microcephaly has been taken in consideration when a newborn is born with the head circumference (HC) below the curve pattern appropriate for the age and gender using reference tables. ${ }^{12-14}$ However, the diagnosis of this event during pregnancy is not accurate and is defined as the cephalic circumference (CC) is measured by ultrasound (USG) and is found to be less than two or three standard deviation below the mean for gestational age. 12,15,16

From a clinical point of view, microcephaly is often associated to intellectual disabilities and neurological disorders. Approximately $90 \%$ of microcephaly are associated to mental retardation, except for constitutional microcephaly of family origin which may have normal cognitive development. ${ }^{12,13}$ Among environmental causes or external microcephaly, the most common are hypoxic-ischemic, vascular alterations, systemic and metabolic disorders, drug exposure during pregnancy (alcohol and chemical products), severe malnutrition in pregnancy (intrauterine), and maternal infections are transmitted during prenatal and perinatal as the classical infections such as rubella, toxoplasmosis, cytomegalovirus, parvovirus, syphilis and herpes and more recently Zika virus at pregnancy. 1,17

In spite of ultrasound usually overestimating prenatal diagnosis for congenital microcephaly, ${ }^{12}$ this is the only method currently available to monitor fetal growth, in obstetric.12-14 The rare occurrence of congenital microcephaly at this moment there is an inexistence of studies to analyze the evolution of cephalic circumference growth during pregnancy.

In Pernambuco State located in the Northeast of Brazil, the State Department of Health (SES/PE) was notified about the increase of children born with microcephaly since August 2015.18 These cases were from different hospital units, either public and private, with maternal and child care attendance in different regions of the State. The increase of the occurrence on congenital microcephaly was attributed to the infection by Zika virus, regarding to the confirmation period of the virus circulating in Brazil. ${ }^{18,19}$

Thus, the objective is to describe and analyze the first cases of congenital Zika virus, by prenatal ultrasound at a referral hospital in Recife, the capital of Pernambuco State, where a great number of congenital microcephaly cases occurred here in 2015.

\section{Methods}

A descriptive study was performed as a type of series of cases in 30 pregnant women who presented an ultrasound diagnosed with fetal altered brain and a clinical suspicion of a previous infection by Zika virus. The women were followed during the period of October to December 2015, at the Fetal Medicine Center for Woman's Care at the Instituto de Medicina Integral Prof. Fernando Figueira (IMIP), a reference hospital to attend cases of microcephaly through the Public Health System. The data were extracted retrospectively from the medical files at the sector of the hospital.

The initial diagnosis of brain alteration in the fetus was conducted at the institution or pregnant women were confirmed by the fetus' malformation. The ultrasound was performed on the equipment of Samsung Medison (Accuvix V20) attached to a convex transducer of 3 to $6 \mathrm{MHz}$. All the patients performed a morphological ultrasound every 15 days, to accompany the cephalic circumference (CC) growth and at least one transvaginal ultrasound was performed when a cephalic was present and for a better assessment of the central nervous system of the fetus aiming to facilitate the diagnosis of intracranial calcifications. The ultrasound exams were performed by one of the two physicians qualified and specialized in Fetal Medicine were chosen exclusively for the research.

The sociodemographic characteristics (maternal age, origin and race), obstetrics (number of abortions, deliveries and previous pregnancies, gestational age for confirmed diagnosis, number of 
prenatal consultations, maternal diseases associated and number of fetuses), prenatal altered ultrasound (the fetal central nervous system morphology and amniotic fluid), the fetus head cephalic circumference growth and perinatal results (gestational age of childbirth, type of delivery, Apgar score at 1 and 5 minutes, birth length, head circumference, thoracic perimeter, birth weight, the newborn's gender, confirmation on prenatal ultrasound finding, live birth, neonatal death, intrauterine hypoxia and the need for neonatal intensive care unit) were analyzed.

The ultrasound was performed on the patient in a comfortable supine position with the bladder properly emptied. The fetal head circumference was measured at the same level of the biparietal diameter cut, around the outer edge of the skull. The biparietal diameter cut was at the level of the thalamus and the cavum of the septum pellucid in not being able to visualize the hemispheres of the cerebellum. 20

Microcephaly was defined as two standard deviations (SD) below the average for gestational age, using Chervenak et al.,21 curve. The ventriculomegaly was diagnosed when the measurement of the posterior lateral ventricle was greater than $10 \mathrm{~mm}$. The cistern magna was considered extended when greater than $10 \mathrm{~mm}$, without morphological alterations of the mid portion of the cerebellum. In the presence of the altered cerebellar vermix, partial or total agenesis diagnosis was suspected. The polyhydramnion was defined when the amniotic fluid indice was greater than $18 \mathrm{~cm}$ and the oligohydramnion when less than $5 \mathrm{~cm}$.

Data analysis was performed on EpiInfo (Atlanta, GA) version 7 program and software R (R Core Team, 2016, Vienna, Austria). Initially, a descriptive analysis was made on the characteristics of the pregnant women. The relation between the fetal head cephalic circumference and gestational age, measured by the ultrasound, were analyzed using logistic random regression effects models based on fractional polynomials, being used to analyze longitudinal data, the polynomials curve is allowed under different structures of temporal dependence among the observations. Following the strategy recommended by Long, 22 eight polynomial models were adjusted by the maximum likelihood means of the method. The selection of the most suitable model was performed using the Akaike information criterion. The $\mathrm{Z}$ test was calculated for the null hypothesis that the instant rate change of the featl head cephalic circumference mean for each gestational age is equal to zero.

This present research was submitted to the Ethics Committee in Research (CEP) in humans at the insti- tution (CAAE number. 57203516.7.0000.5201) and only began this research after it was approved. A request for a waiver on the informed consent form was solicitated because this is a retrospective study, which it is not feasible to obtain consent from all the women who already were submitted to ultrasound.

\section{Results}

The women had a mean age of $24.5 \pm 6.9$ years, ranging from 15 to 37 years old, most of them were from the city of Recife (50\%), and from other towns in the metropolitan region and declared to have dark skin (Table 1).

The mean gestational age at which the diagnosis of the altered brain ultrasound was confirmed, at $33.3 \pm 4.7$ weeks, varying from 22 nd to 41 st week. The median number of previous abortions was zero, the number of births and previous pregnancies was one and the number of prenatal consultations were seven. All the women had only one pregnancy and $23.3 \%$ of them reported having a diagnosis of some chronic disease, such as diabetes, hypertension or heart disease (Table 1).

The main alteration of the fetal's brain by ultrasound was microcephaly $(n=29 ; 96.7 \%)$, followed by ventriculomegaly, intracranial calcification, uneven cranial curve, extended cistern magna, total and partial agenesis of the vermix cerebellar ataxia and one case of macrocrania. In one fetus was detected with alterations of the members, three were polyhydramnion and one oligohydramnion (Table 2).

As to the perinatal outcomes and the delivery, the mean gestational age observed was $38.9 \pm 1.3$ weeks, ranging from 37 th to 41 st weeks. The vaginal delivery occurred in most of the cases $(76.7 \%)$ and the median Apgar scores at 1 and 5 minutes was nine. The mean birth length was $46.2 \mathrm{~cm}$, the head circumference was $28.9 \mathrm{~cm}$, the thoracic perimeter was $33.1 \mathrm{~cm}$ and birth weight, of 2,854.8 grams. Half of the newborns were males and all altered prenatal ultrasound including microcephaly were confirmed by clinical examination and postnatal imaging (Table 3). It should be emphasized that the alterations of the members observed in one of the fetuses was described as fetal akinesia/arthrogryposis syndrome. There were no cases of neonatal death, intrauterine hypoxia and the need for a neonatal intensive care unit. However, there was a stillborn and the family members did not allow to perform a histopathological examination.

The analysis of the fetus' head cephalic circumference demonstrated an increase in the estimated average circumference is according to the gestational 
Sociodemographic characteristics and obstetric of women with altered fetal ultrasounds suspected of congenital Zika virus syndrome.

\begin{tabular}{|c|c|c|}
\hline Characteristics $(n=30)$ & & \\
\hline Maternal Age (years): $\bar{X} \pm D P$ & 24.5 & 6.9 \\
\hline Maternal Age (years): Variation & $15-37$ & \\
\hline \multicolumn{3}{|l|}{ Location } \\
\hline Recife and Metropolitan region $(\mathrm{n} ;(\%)$ & 15 & 50.0 \\
\hline Backland $(n ;(\%)$ & 06 & 20.0 \\
\hline Forest Zone (n; (\%) & 05 & 16.7 \\
\hline Desert Lands (n; (\%) & 04 & 13.3 \\
\hline \multicolumn{3}{|l|}{ Race/color } \\
\hline Dark skin $(n ;(\%)$ & 15 & 50.0 \\
\hline Black $(n ;(\%)$ & 09 & 30.0 \\
\hline White $(n ;(\%)$ & 06 & 20.0 \\
\hline Gestational age of the diagnosic (weeks): $\bar{X} \pm$ DP & 33.3 & 4.7 \\
\hline Gestational age of the diagnosic (weeks): Variation & $22-41$ & \\
\hline Number of previous abortions (median, IIQ) & 0 & $0-0$ \\
\hline Number of previous pregnancies (median, IIQ) & 1 & $0-2$ \\
\hline Number of previous births (median, IIQ) & 1 & $0-1$ \\
\hline Number of prenatal visits (median, IIQ) & 7 & $6-9$ \\
\hline Associated diseases (diabetes, hypertension and heart disease) ( $n ; \%)$ & 7 & 23.3 \\
\hline Only one pregnancy $(n ; \%)$ & 30 & 100.0 \\
\hline
\end{tabular}

$\mathrm{IIQ}=$ interquartile interval.

Table 2

Alterations in the prenatal ultrasound in fetuses suspected of congenital Zika virus syndrome.

\begin{tabular}{lcc}
\hline Alterations in prenatal ultrasound & $\mathbf{N}$ & \% \\
\hline Alterations of the Brain & 30 & 100.0 \\
$\quad$ Microcephaly & 29 & 96.7 \\
Ventriculomegaly & 22 & 16.3 \\
Intracranial calcifications & 11 & 53.3 \\
Irregular curve & 02 & 36.7 \\
Extended Cistern magna & 02 \\
Partial agenesis of the cerebellar vermix & 02 \\
Total agenesis of the cerebellar vermix & 01 \\
Macrocrania & 6.7 \\
Polyhydramnion & 03 \\
Oligohydramnion & 01 \\
Altered another system (limbs) & 3.3 \\
\end{tabular}


Perinatal Outcomes of newborns ultrasound suspected of congenital Zika virus syndrome.

\begin{tabular}{lc}
\hline Perinatal Outcomes & $39 \pm 1.3$ \\
\hline Gestational Age delivery (weeks): $\bar{X} \pm$ DP & $37-41$ \\
Gestational Age delivery (weeks): Variation & $23 ; 76.7 \%$ \\
Vaginal delivery ( $\mathrm{n}$ \%) & $9 ; 8-9$ \\
Apgar score at 1 min. (median; IIQ) & $9 ; 9-10$ \\
Apgar score at 5 min. (median; IIQ) & $46.2 \pm 1.9$ \\
Birth length (cm): $\bar{X} \pm$ DP & $40-49$ \\
Birth length (cm): Variation & $28.9 \pm 1.6$ \\
Head circumference (cm): $\bar{X} \pm$ DP & $27-34$ \\
Head circumference (cm): Variation & $33.1 \pm 4.7$ \\
Thoracic perimeter (cm): $\bar{X} \pm$ DP & $29-53$ \\
Thoracic perimeter (cm): Variation & $2,854.8 \pm 304.2$ \\
Birth weight (grams): $\bar{X} \pm$ DP & $2,250.0-3,385.0$ \\
Birth weight (grams): Variation & $15 ; 50.0 \%$ \\
Male Gender ( $\mathrm{n}$; $)$ & \\
\hline
\end{tabular}

$\mathrm{IIQ}=$ interquartile interval.

\section{Table 4}

Fetal head cephalic circumference (CC) mean and estimated rate of instant variation of CC mean (mm/week), according to gestational age assessed by ultrasound in fetuses suspected of congenital Zika virus syndrome.

\begin{tabular}{|c|c|c|c|}
\hline Gestational Age (weeks) & Fetal head cephalic circumference Mean ( $\mathrm{mm}$ ) & Rate Variation (mm/week) & $p^{*}$ \\
\hline 20 & 148.7 & 14.73 & $<0.001$ \\
\hline 22 & 174.3 & 11.07 & $<0.001$ \\
\hline 24 & 193.7 & 8.52 & $<0.001$ \\
\hline 26 & 208.8 & 6.70 & $<0.001$ \\
\hline 28 & 220.8 & 5.37 & $<0.001$ \\
\hline 30 & 230.5 & 4.36 & $<0.001$ \\
\hline 32 & 238.5 & 3.60 & $<0.001$ \\
\hline 34 & 245.0 & 3.00 & $<0.001$ \\
\hline 36 & 250.5 & 2.53 & $<0.001$ \\
\hline 38 & 255.2 & 2.15 & $<0.001$ \\
\hline 40 & 259.2 & 1.84 & $<0.001$ \\
\hline
\end{tabular}

* Z test; $95 \% \mathrm{Cl}=95 \%$ of confidence interval. 
Relation between Fetal head cephalic circumference (CC) and gestational age assessed by ultrasound in fetuses suspected of congenital Zika virus syndrome. The curve (full line) corresponds to Fetal head cephalic circumference mean for gestational age.

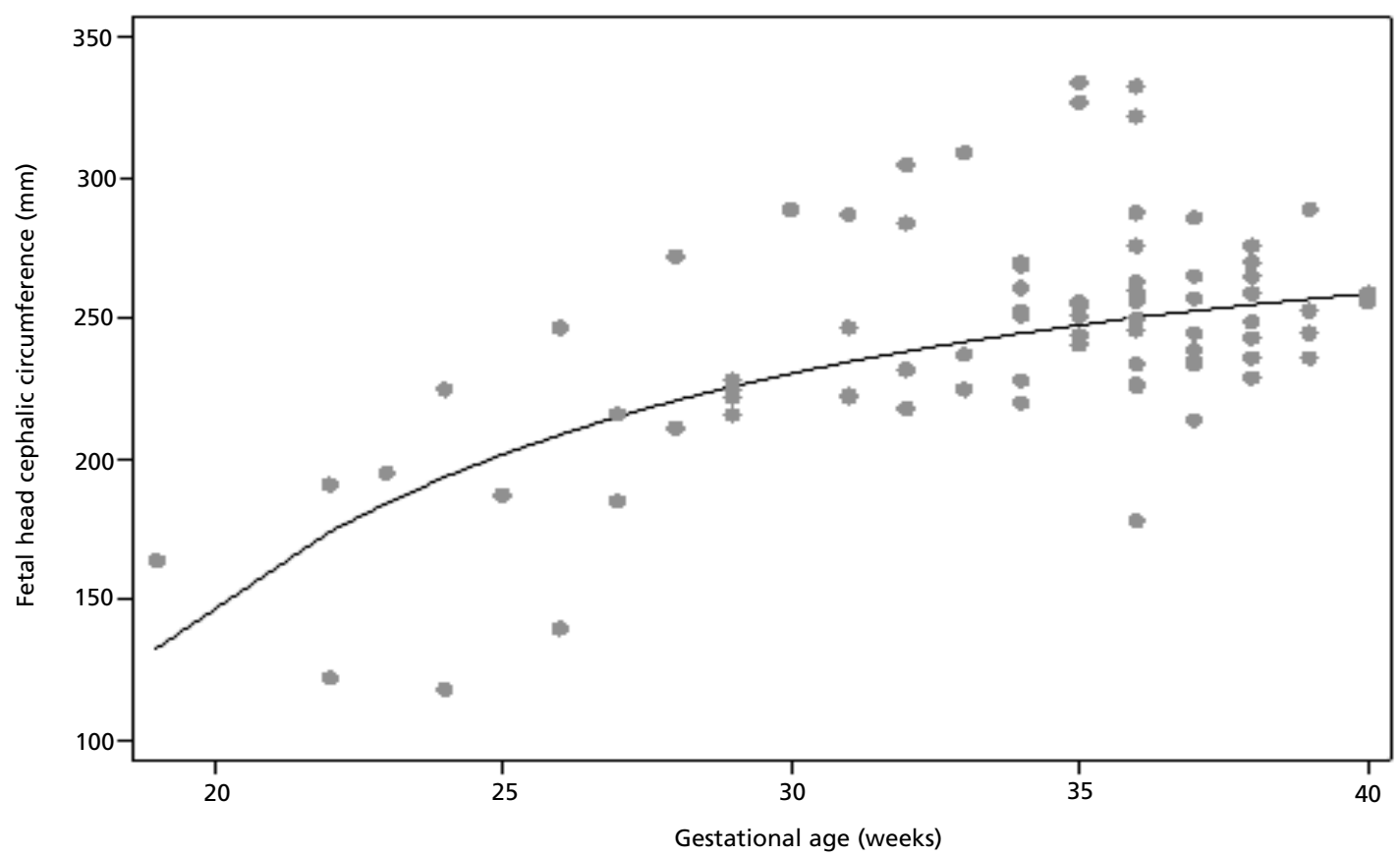

age assessed by the ultrasound (Table 4) and a nonlinear form (Figure 1). We also observed that the altered rate of the instant fetal head cephalic circumference mean was statistically significant, suggesting an increase in the circumference according to the gestational age and that this variation decreased with the gestational age (Table 4).

\section{Discussion}

The fetal microcephaly was found in 29 of the 30 cases analyzed and constituted of the main altered neurological ultrasound in cases of presumed congenital infection by ZIKV in this outbreak. Other findings of neurological ultrasound found in this study have also been described in other articles that congenital infection of ZIKV was confirmed by PCR in the amniotic fluid of the fetus. 2,3 There is has a direct relation with the reduction of brain parenchyma of the fetus resulting from infection, mainly, the progenitor cells of cortical neurons. 9,10 Experimental studies on gene expression showed that ZIKV is a neurotropic causing cell death by apoptosis and neuronal autophagy. 10

The ultrasound diagnosis was performed early in some patients while in others these findings were observed later in the 41 st week. This difference in the gestational age of the diagnosis was a result of the period in which the patient was sent to the Fetal Care Medicine Service at IMIP and not at the time of the morphological alterations onset. In addition, the difficulty to have access for diagnostic tests during prenatal care such as ultrasound, but it was not allowed earlier diagnosis.

It is important to emphasize that a high percentage of these women was in the course of their first pregnancy, causing all of them to have their first experience as mothers with suspected congenital infection by Zika virus (ZIKV), in fact a strong emotional and social impact.

Most of the pregnant women came from places with high infestation of Aedes $s p$., in other words, in Recife, Pernambuco and the metropolitan region. 16 The increased incidence of microcephaly was identi- 
fied in Pernambuco, ${ }^{16}$ where the suggested hypothesis in associating ZIKV and microcephaly, subsequently the virus was also discovered in the amniotic fluid of pregnant women with fetuses presenting microcephaly and other malformations in Paraíba. ${ }^{2}$

In one of the cases in this study, we observed that macrocrania was associated to ventriculomegaly and agenesis of the cerebellar vermix. This finding reinforces not only microcephaly can be found in cases of suspected congenital ZIKV, though depending on the brain alterations associated to hydrocephalus, macrocrania can also be observed, although much rarer due to the increased intracranial pressure. It should be emphasized that there were no reports of macrocrania associated to ZIKV and that in this study laboratorial tests were not possible to be performed knowing that the first pregnant women infected with a suggestive infection of ZIKV and that the fetal alteration diagnosed in the intrauterine in this service, and the protocol to carry out the examinations had not been yet developed.

The alteration of the amniotic fluid volume for ultrasound was also observed, but the finding is not available for the histopathological finding of the placenta to evaluate possible viral effects at the placental level. Other studies suggest an increase in the volume of the amniotic fluid in these pregnant women, particularly when some alteration is present in the brain. 23,24

In spite of the morphological alterations possibly related to ZIKV, the increase in the rate of prematurity was not observed. The normal delivery could be carried out without any major complications and with great Apgar scores at 1 and 5 minutes reinforcing that there is no indication for cesarean birth in congenital infection by ZIKV. In addition, there were no cases of neonatal death, intrauterine hypoxia or the need for neonatal intensive care unit. Actually, it is questioned the necessity of these births to occur at a service of high risk even in the presence of suspected congenital infection by ZIKV. However, after the birth, the newborns with morphological alterations will need to be taken to a reference service for neonatal microcephaly/ZIKV for evaluation and monitoring. 6

The lowest mean of length and weight at birth can be justified by a possible restriction of intrauterine growth in agreement with other studies that describe congenital infection by ZIKV.25,26 However, most of these newborn infants were classified as appropriate for gestational age. Emphasizing that the alteration of the members observed in one of the fetuses was described as a fetal akinesia/arthrogryposis syndrome, in which another study has suggested the association to ZIKV.25 There was a stillborn, but the family members did not allow to perform any histopathological examination.

Based on these results, we propose some care regarding to women with a history of rash during the pregnancy, with suspected ultrasound on congenital infection by ZIKV, with or without laboratorial confirmation on ZIKV, though, the results do not always arrive in time for the delivery.

A conduct is suggested in always being conservative, especially when the infection is next to the delivery. The newborn should be carefully monitored in his/her clinical evolution until the second week of life and the puerperal should be monitored intensively principally regarding the possibility of uterine bleeding.

The delivery in the presence of arboviroses is always obstetric. There is no indication of cesarean section due to the fact that pregnant woman have or is with ZIKV or by fetal microcephaly. During the evolution of labor, it is necessary to observe the presence of fever in pregnant women, because in addition to maternal dehydration it may cause tachycardia in the fetus and confuse the clinical assessment by thinking that we are facing a case of acute fetal distress.

By chance the pregnant woman was infected in the last 15 days prior to the delivery, there is the possibility of transmitting ZIKV to the fetus at the time of delivery, the clamping of the umbilical cord should be early. If the infection occurred more than 15 days from the date of the delivery, the conduct then is the same for all the pregnant women, in other words, clamping the umbilical cord after the stop of the pulse. This procedure helps to reduce the chances of anemia in the newborn's first year of life. 27

The most relevant finding in this study was to determine that even after the microcephaly has been installed and diagnosed by prenatal ultrasound, the fetus head cephalic circumference continues to grow until the birth, but with the growth rate less than expected. It was also observed that this growth is not linear, in other words, the gestational ages get closer to the birth, the growth rate tends to decrease. Thus, it is suggested that fetuses with microcephaly occur a deviation in the curve growth of the cephalic circumference going downward, due to a lower growth rate when compared to a normal fetus. ${ }^{21}$ Similar studies are not available in the world literature, however it is necessary to develop new studies with a larger sample number and control group.

We conclude that the main fetal morphological alteration is microcephaly, which presents a growth of a fetal head cephalic circumference according to the gestational age in a non-linear form and that the variation decreases with the gestational age. 


\section{References}

1. Besnard $\mathrm{M}$, Lastère $\mathrm{S}$, Teissier $\mathrm{A}$, Cao-Lormeau VM, Musso D. Evidence of perinatal transmission of Zika virus, French Polynesia, December 2013 and February 2014. Euro Surveill. 2014; 19 (13): 20751.

2. Melo ASO, Malinger G, Ximenes R, Szejnfeld PO, Alves Sampaio S, Bispo de Filippis AM. Physician Alert. Ultrasound Obstet Gynecol. 2016; 47: 6-7.

3. Mlakar J, Korva M, Tul N, Popović M, Poljšak-Prijatelj M, Mraz J, Kolenc M, ResmanRus K, Vipotnik TV, Vodušek VF, Vizjak A, Pižem J, Petrovec M, Županc TA. ZikaVirus associated with microcephaly. N Engl J Med. 2016. DOI: 10.1056/NEJMoa1600651

4. Rasmussen SA, Jamieson DJ et al. Zika virus and birth defects- reviewing the evidence for causality. N Engl J Med. 2016; 374 (20): 1981-7

5. Panchaud, A, Stojanov M et al. Emerging role of Zika virus in adverse fetal and neonatal outcomes. Clin Microl Rev. 2016; 29 (3): 659-94

6. Leibovitz Z, Daniel-Spiegel E, Malinger G, Haratz K, Tamarkin M, Gindes L, Ben-Sira L, Lev D, Shapiro I, Bakry H, Weizman B, Zreik A, Egenburg S, Arad A, Tepper R, Kidron D, Lerman-Sagie T. Microcephaly at birth using three references for fetal head circumference: can we improve prenatal diagnosis? Ultrasound Obstet Gynecol. 2016; 47 (5): 586-92.

7. Foy BD, Kobylinski KC, ChilsonFoy JL, Blitvich BJ Travassos da Rosa A, Haddow AD, Lanciotti RS, Tesh RB. Probable non-vector-borne transmission of Zika virus, Colorado, USA. Emerg Infect Dis. 2011; 17(15): 880-2.

8. Cardoso CW, Paploski IAD, Kikuti M, Rodrigues MS Silva MMO, Campos GE, et al. Outbreak of acute exanthema to us illness associated with Zika, chikungunya, and dengue viruses, Salvador, Brazil [letter]. Emerg Infect Dis. 2015; 21 (12).

9. Brasil. Ministério da Saúde. Protocolo de Vigilância e resposta á ocorrência de microcefalia e/ou alterações do sistema nervoso central (SNC)/Ministério da Saúde, Secretaria de Vigilância em Saúde. Departamento de Vigilância das Doenças Transmissíveis. Brasília; 2015 55p. www.saude.gov.br/svs.

10. Fenton TR, Kim JH. A systematic review and meta-analysis to revise the Fenton growth chart for preterm infants. BMC Pediatr. 2013; 13: 59

11. Fenton TR. A new growth chart for preterm babies: Babson and Benda's chart updated with recent data and a new format. BMC Pediatr. 2003; 3: 13

12. WHO Multicentre Growth Reference Study Group. WHO Child Growth Standards: Head circumference-for-age, arm circumference-for-age, triceps skin fold-for-age and subscapular skin fold-for-age: Methods and development. Geneva: World Health Organization. 2007; 217 p.

13. Pernambuco. Secretaria Estadual de Saúde de Pernambuco. Secretaria Executiva de Vigilância em Saúde. Protocolo Clínico e Epidemiológico para investigação de casos de microcefalia no estado de Pernambuco. Versão $\mathrm{N}^{\circ} 02$ Pernambuco: Secretaria Estadual de Saúde; 2015. 42p.
14. Barthel A, Gourinat AC, Cazorla C, Joubert C, DupontRouzeyrol M, Descloux E. Breast milk as a possible route of vertical transmission of dengue virus? Clin Infect Dis. 2013; 57 (3): 415-7.

15. Tan PC, Rajasingam G, Devi S, Omar SZ. Dengue infection in pregnancy: prevalence, vertical transmission, and pregnancy outcome. Obstet Gynecol. 2008; 111 (5): 1111-7.

16. Basurko C, Carles G, Youssef M, Guindi WE. Maternal and foetal consequences of dengue fever during pregnancy. Eur J Obstet Gynecol Reprod Biol. 2009; 147 (1): 29-32.

17. Tang H, Hammack C, Ogden SC, Wen Z, Qian X, Li Y, Yao B, Shin J, Zhang F, Lee EM, Christian KM, Didier RA, Jin P, Song H, Ming GL. Zika virus infects human cortical neural progenitors and attenuates their growth. Cell Stem Cell. 2016; 5; 18 (5): 587-90.

18. Cugola FR, Fernandes IR, Russo FB, Freitas BC, Dias JL, Guimarães KP, Benazzato C, Almeida N, Pignatari GC, Romero S, Polonio CM, Cunha I, Freitas CL, Brandão WN, Rossato C, Andrade DG, Faria DP, Garcez AT, Buchpigel CA, Braconi CT, Mendes E, Sall AA, Zanotto PM, Peron JP, Muotri AR, Beltrão-Braga PC. The Brazilian Zika virus strain causes birth defects in experimental models. Nature. 2016; 534 (7606): 267-71.

19. Centers for Disease Control and Prevention. CDC concludes Zika causes microcephaly and other birth defects. http://www.cdc.gov/media/releases/2016/s0413zika-microcephaly.html. [acessado em: 20/06/2016].

20. American Institute of Ultrasound in Medicine. AIUM practice guideline for the performance of obstetric ultrasound examinations. J Ultrasound Med. 2013; 32: 1083-101. doi:10.7863/ultra.32.6.1083.

21. Chervenak FA, Rosenberg J, Brightman RC, Chitkara U, Jeanty P. A prospective study of the accuracy of ultrasound in predicting fetal microcephaly. Obstet Gynecol. 1987; 69 (6): $908-10$

22. Long JD. Longitudinal data analysis for the behavioral sciences using R. Sage Publication, Inc. Los Angeles; 2012.

23. Lin CY, Chen CP, Liau CL, Su PH, Tsao TF, Chang TY, Wang W. Prenatal diagnosis of monosomy 17p (17p13.3-$>$ pter) associated with polyhydramnios, intrauterine growth restriction, ventriculomegaly, and Miller-Dieker lissencephaly syndrome in a fetus. Taiwan J Obstet Gynecol. 2009; 48 (4): 408-11.

24. Chen CP, Chern SR, Tsai EJ, Lee CC, Chen LF, Wang W. Prenatal diagnosis of partial trisomy 14q (14q31.1-->qter) and partial monosomy $5 \mathrm{p}$ (5p13.2-->pter) associated with polyhydramnios, short limbs, micropenis and brain malformations. Genet Couns. 2009; 20 (3): 281-8.

25. Schuler-Faccini L, Ribeiro E, Feitosa IML, Horovitz DDG, Cavalcanti DP, Pessoa A, Doriqui MJR, et al. Possível associação entre a infecção pelo vírus zika e a microcefalia Brasil, 2015. MMWR. 2016; 65 (3). [acesso em 20 jun 2016]. http://www.cdc.gov/mmwr/volumes/65/wr/pdfs/ mm6503e2_Portuguese.pdf. 
26. Brasil P, Pereira JP Jr, Raja Gabaglia C, Damasceno L, Wakimoto M, Ribeiro Nogueira RM, Carvalho de Sequeira $\mathrm{P}$, et al. Zika Virus Infection in Pregnant Women in Rio de Janeiro - Preliminary Report. N Engl J Med. 2016. DOI: 10.1056/NEJMoa1602412

Received on July 5, 2016

Final version presented on September 13, 2016

Approved on September 27, 2016
27. Brasil. Ministério da Saúde. Diretriz Nacional de Assistência ao Parto Normal/Ministério da Saúde, Comissão Nacional de Incorporação de Tecnologias no SUS (CONITEC). Brasília: Ministério da Saúde, 2016. 381p. http://conitec.gov.br/images/Consultas/2016/ Relatorio_Diretriz-PartoNormal_CP.pdf. 